\title{
A new euarthropod with large frontal appendages from the early Cambrian Chengjiang biota
}

\author{
Robert J. O'Flynn, Mark Williams, Mengxiao Yu, Thomas H.P. Harvey, and Yu Liu
}

\begin{abstract}
We describe Fengzhengia mamingae gen. et sp. nov., a new euarthropod from the lower Cambrian (Series 2, Stage 3) Chengjiang Lagerstätte, Southwest China. Fengzhengia mamingae possesses prominent frontal appendages, stalked, circular eyes, a simple, sub-triangular head shield, and a trunk with 15 tergites, the anterior nine each bearing a single medial axial spine. Limited evidence suggests biramous trunk appendages with paddle-shaped exopods. At the posterior end is a sub-triangular region, possibly a pygidium, articulated with a tail fan. The frontal appendage of $F$. mamingae resembles those of certain 'great appendage' arthropods and Isoxys. We test the affinities of F. mamingae by parsimony and Bayesian analyses and tentatively suggest that it is an early branch of Deuteropoda. We suggest that $F$. mamingae may have been a nektobenthic scavenger or predator, and its dorsal exoskeleton is notable for exhibiting defensive spines.
\end{abstract}

Robert J. O'Flynn. Yunnan Key Laboratory for Palaeobiology, Institute of Palaeontology, Yunnan University, 650500 Kunming, China and School of Geography, Geology and the Environment, University of Leicester, University Road, Leicester, LE1 7RH, UK and MEC International Joint Laboratory for Palaeobiology and Palaeoenvironment, Yunnan University, 650500 Kunming, China. rjof1@leicester.ac.uk http://orcid.org/0000-0001-9939-6321

Mark Williams. School of Geography, Geology and the Environment, University of Leicester, University Road, Leicester, LE1 7RH, UK and MEC International Joint Laboratory for Palaeobiology and Palaeoenvironment, Yunnan University, 650500 Kunming, China. mri@leicester.ac.uk http://orcid.org/0000-0002-7987-6069

Mengxiao Yu. Yunnan Key Laboratory for Palaeobiology, Institute of Palaeontology, Yunnan University, 650500 Kunming, China and MEC International Joint Laboratory for Palaeobiology and Palaeoenvironment, Yunnan University, 650500 Kunming, China, mengxiao.yu@mail.ynu.edu.cn https://orcid.org/0000-0003-3671-0584

http://zoobank.org/454132D3-421B-4F8F-ADB7-F9F629070902

O’Flynn, Robert J., Williams, Mark, Yu, Mengxiao, Harvey, Thomas H.P., and Liu, Yu. 2022. A new euarthropod with large frontal appendages from the early Cambrian Chengjiang biota. Palaeontologia Electronica, 25(1):a6. https://doi.org/10.26879/1167 palaeo-electronica.org/content/2022/3551-a-new-chengjiang-euarthropod

Copyright: February 2022 Paleontological Society.

This is an open access article distributed under the terms of Attribution-NonCommercial-ShareAlike 4.0 International (CC BY-NC-SA 4.0), which permits users to copy and redistribute the material in any medium or format, provided it is not used for commercial purposes and the original author and source are credited, with indications if any changes are made.

creativecommons.org/licenses/by-nc-sa/4.0/ 
Thomas H.P. Harvey. School of Geography, Geology and the Environment, University of Leicester, University Road, Leicester, LE1 7RH, UK and MEC International Joint Laboratory for Palaeobiology and Palaeoenvironment, Yunnan University, 650500 Kunming, China. thph2@leicester.ac.uk http://orcid.org/0000-0002-2717-7004

Yu Liu. Yunnan Key Laboratory for Palaeobiology, Institute of Palaeontology, Yunnan University, 650500 Kunming, China and MEC International Joint Laboratory for Palaeobiology and Palaeoenvironment, Yunnan University, 650500 Kunming, China. yu.liu@ynu.edu.cn http://orcid.org/0000-0002-2346-740X (corresponding author)

Keywords: lower Cambrian; Chengjiang; Euarthropoda; new genus; new species

Submission: 21 May 2021. Acceptance: 27 January 2022.

\section{INTRODUCTION}

The lower Cambrian (Series 2, Stage 3) Chengjiang biota of China's Yunnan Province is famous for its diversity of exceptionally preserved fossil organisms. Over 250 species have been described and of these about one-third are arthropods. These taxa have provided important morphological information bearing on the evolution of early arthropods (see Hou et al., 2017 and references therein).

The Chengjiang biota provides fossils with particular interest for assessing the character transitions leading to the evolution of Deuteropoda, a group that includes 'upper' stem and crown-group euarthropods (Ortega-Hernández, 2016; Daley et al., 2018). The 'lower' part of the euarthropod stem is occupied by lobopodians and radiodonts, whereas the 'upper' part contains several groups with fully arthrodised bodies and biramous appendages (reviewed in Ortega-Hernández, 2016; Daley et al., 2018). The euarthropods of the Chengjiang biota have the potential to reveal the origins of the major crown lineages, i.e., modern chelicerates and mandibulates (Ortega-Hernández, 2016), but the constituent groups and their interrelationships are a matter of dispute. Major challenges remain in resolving the phylogenetic status and positions of the megacheirans ('great appendage' euarthropods), artiopodans (including trilobites and relatives), fuxianhuiids, and various bivalved arthropods (see Budd, 2021 for a review of competing hypotheses). Attention has focussed on the implied major rearrangement of the arthropod head in this region of the tree (Ortega-Hernández et al., 2017). However, accurate interpretation of pivotal characters, such as the segmental identity of the prominent head appendages, and the presence and location of a labrum, require exceptional fossil evidence such as preserved neural tissue (e.g., Ma et al., 2012; Tanaka et al., 2013; Cong et al., 2014; Strausfeld et al., 2016; Ortega-Hernández et al., 2019; Budd, 2021) and three-dimensional information on the ventral head region (e.g., Liu et al., 2020) - and even then, divergent interpretations can be considered (Aria et al., 2020; Budd, 2021).

Another approach, however, is to document new taxa from the 'upper' stem-group of euarthropods, in which novel character combinations can potentially help polarise character transformations (Budd, 1996; Daley et al., 2009; Smith and OrtegaHernández, 2014; Vannier et al., 2014; OrtegaHernández et al., 2017; Daley et al., 2018; Zeng et al., 2020). Recently, for example, the description of Kylinxia zhangi Zeng, Zhao, and Huang in Zeng et al., 2020 has documented apparently radiodonttype frontal appendages and opabiniid-type eyes in a euarthropod that otherwise resembles a megacheiran (Zeng et al., 2020), whereas Bushizheia yangi O'Flynn and Liu in O'Flynn et al., 2020 apparently combines a 'great appendage'like frontal appendage with a body form and pygidium more typical of certain artiopodans (O'Flynn et al., 2020).

Here we describe Fengzhengia mamingae gen. et sp. nov., an exceptionally rare component of the Chengjiang arthropod assemblage. Although incompletely preserved and known from only one specimen, F. mamingae displays morphological characteristics (e.g., body arthrodisation and limbbiramy) that suggest it is an early branch of Deuteropoda (Ortega-Hernández, 2016, table 4). We evaluate its morphology, most notably the significance of its large frontal appendages and posterior shield-like structure (a possible pygidium), articulated with a tail fan. We test the likely phylogenetic position of this species using parsimony and Bayesian phylogenetic analyses. 


\section{MATERIALS AND METHODS}

\section{Material}

A single specimen (part and counterpart) of Fengzhengia mamingae was recovered from the Yu'anshan Member, Chiungchussu Formation at Jiucun Town ( $24^{\circ} 41^{\prime} 33^{\prime \prime} \mathrm{N}, 102^{\circ} 59^{\prime} 26^{\prime \prime}$ E), Chengjiang County (Du et al., 2018). The Yu'anshan Member is informally subdivided into four successive lithologically and palaeontologically distinctive parts (Zhu et al., 2001). Fengzhengia mamingae was recovered from the third stratigraphic unit of the Yu'anshan Member from laminated mudstones of the lower Cambrian (Series 2, Stage 3). The specimen is deposited in the Yunnan Key Laboratory for Palaeobiology (YKLP 11431) at Yunnan University, Kunming. The specimen was prepared mechanically with a mounted steel needle under a binocular microscope, where only a small amount of matrix was required to be removed.

\section{Photography and CT Imaging}

Fluorescence microscopy and photography (a Leica DFC7000 T linked to a Leica M205 FA fluorescence stereo microscope) were used to increase the contrast between the specimen (not autofluorescent) and the matrix (weakly autofluorescent). For photographs in natural colour, several images of the fossil were captured with the aid of the Keyence VHX-6000 Digital Microscope (Keyence International, Belgium), either with ring light type illumination (Haug et al., 2018) or cross-polarised co-axial illumination (Haug et al., 2013) to limit reflection of light and increase contrast (Bengtson, 2000). The focus-stacking function of the digital microscope was used to create in-focus images of three-dimensional objects despite the limitation of the depth-of-field: all photographs presented are composite images (Haug et al., 2008, 2011). We used stereo photography to help convey further morphological information for both part and counterpart. The specimen was also investigated with computed tomography using a ZEISS Xradia 520 Versa.

\section{Measurements}

Measurements were made on digital photographs using the image processing software ImageJ (Schneider et al., 2012). Morphological characters measured include: (1) the total length, measured from the anterior margin of the head shield to the posterior termination of the tail fan; (2) the head shield, measured from the anterior margin to the posterior margin; (3) tergites one through
15 , measured from the anterior margin to the posterior margin of the tergite; (4) the posterior shieldlike structure, measured from the posterior margin of the posterior most tergite to the posterior termination; (5) the tail fan, measured from the posterior margin of the posterior shield to the posterior termination; and (6) the frontal head limb, measured from the distal termination to the proximal margin of the podomeres.

\section{Parsimony and Bayesian Analyses}

To test the phylogenetic position of Fengzhengia mamingae a series of analyses were performed using the data matrix of Zeng et al. (2020) (see their supplementary information) with F. mamingae, Kiisortoqia soperi Stein, 2010, and Bushizheia yangi added; this dataset represents a large sample, with comprehensive coverage of stem-euarthropods (Appendices 1-4), and thus provides a robust framework in which to test hypotheses. The matrix includes 283 characters and 84 taxa. The priapulid Priapulus caudatus is regarded as the outgroup as in the studies of Aria et al. (2020) and Zeng et al. (2020). Panarthropod representatives including tardigrades, onychophorans, lobopodians, Radiodonta Collins, 1996, Megacheira Hou and Bergström, 1997, Fuxianhuiida Bousfield, 1995, and Artiopoda Hou and Bergström, 1997 are also included. The data matrix was built in WinClada 1.00.08 (Nixon, 1999), and the parsimony analysis was performed with TNT (Tree analysis using New Technology) 1.5 (Goloboff and Catalano, 2016). The software was set to retain 10,000 trees in memory and perform 10,000 replications. Each analysis included a traditional search with tree bisection and reconnection, a random seed of one and 1,000 trees to save per replicate. The optimal trees found in traditional searches were verified by new technology searches with 1,000 random addition sequences. Strict consensus trees were used to summarise the results of parsimony analyses. Because of uncertainty in the interpretation of certain structures in F. mamingae, we performed four sensitivity analyses to test the effects of coding for the presence of a pygidium, and of alternative interpretations of the insertion point of the frontal appendage, reflecting uncertainty in the segmental homology of frontal appendages in cases where the insertion point and neural innervation pattern cannot be confirmed (Budd, 2021). To test the sensitivity of the results to alternative hypotheses for the homology of the large frontal appendage of $F$. mamingae, we conducted experimental analyses coding it as deutocerebral 
(Appendix 1), unknown (Appendix 2), and protocerebral (Appendix 3), respectively. In analyses 1 to 3 we included a pygidium, and in analysis 4 (Appendix 4) we excluded this.

Bayesian phylogenetic inference of the same data matrix was conducted in MrBayes 3.2.7 (Ronquist et al., 2012). A run of 50,000,000 Markov chain Monte Carlo generations was performed, each containing four Markov chains under the Mkv $+\Gamma$ model for discrete morphological character data (Lewis, 2001). Trees were collected by a sampling frequency of 1,000 generations and with the first $25 \%$ discarded as burn-in. Convergence, corroborated graphically in Tracer v1.7.2 (Rambaut et al., 2018), was indicated by standard deviation of split frequencies below 0.003 . A $50 \%$ majority-rule consensus tree of the remaining tree samples was calculated and used as a summary of results.

\section{SYSTEMATIC PALAEONTOLOGY}

Phylum Euarthropoda Lankester, 1904

Class, Order, and Family incertae sedis

Genus Fengzhengia new genus

zoobank.org/3B72CDB4-5DE5-40AE-87B6-89B478FAAE63

Fengzhengia mamingae new species

zoobank.org/302FEF94-956A-4743-BD44-E67DCF3D70FC

Figures 1A-C, 2A-C, 3A-C, 4A-C, 5A-J, 6A-C

Type species. Fengzhengia mamingae gen. et sp. nov., by monotypy.

Type material. Holotype, YKLP 11431 (part: Figures 1A-C, 2A-C, 3A-C, 5A, E-J, 6A-C; counterpart: Figures $4 A-C, 5 B-D)$ from the Cambrian, Series 2, Stage 3, Eoredlichia-Wutingaspis trilobite biozone, Nangoan Stage of regional Chinese usage, Yu'anshan Member, Chiungchussu Formation (Repository: YKLP).

Diagnosis. Euarthropod possessing pair of upward-orientated frontal-most appendages, each consisting of stout shaft and distal articulated region composed of at least six podomeres, five of which clearly bear elongate triangular endites. Two anterior and no posterior stalked compound eyes. Head shield with rounded genal angles. Trunk consisting of 15 tergites - anterior-most nine bearing medial axial spines. Biramous trunk appendages with paddle-shaped exopods fringed with setae. Posterior shield-like structure merged from $\geq$ three somites articulated with tail fan.

Etymology. Genus name from 风筝 fēngzhēng, Mandarin, kite, i.e., a quadrilateral whose four sides can be grouped into two pairs of equal-length sides that are adjacent to each other, with reference to the overall shape of the fossil. Species from 马明 Mă Míng, the wife of 杨志金金 Yáng Zhìxin of Kunming, the man who recovered and prepared the fossil.

Description. Lateral aspect of the head shield, trunk, posterior shield-like structure, and tail fan (Figures 1A-C, 5A, E-J, 6A-C; Table 1): the overall outline of Fengzhengia mamingae is sub-quadrilateral, making a kite-shape whose maximum length is circa $38 \mathrm{~mm}$. It is laterally compressed, lies parallel to lamination, and is well-articulated, i.e., the tergites are preserved attached and the left eye is preserved in situ.

The head shield is simple and sub-triangular with a medial axial spine (Figure $1 \mathrm{~A}-\mathrm{C}$ ), smoothly rounded posterolateral margins, and its length, which is comparable to its width, is circa one-third of the total length of the body.

The trunk tapers very gently from the first and second tergites, which are of equivalent size, to the ninth tergite, each one of which possesses a medial axial spine. Tergites $10-15$ are comparatively short and narrow: tergite 10 is characterised by an abrupt change in length and width compared to the preceding tergite (tergite 9). These short and narrow tergites, without medial axial spines, taper backward to a posterior shield-like structure to which a tail fan is attached. All tergites curve posteriorly (Figure 3A-C).

The posterior shield-like structure (Figure 6AC), is sub-triangular, appears to consist of at least three fused segments, and covers at least one putative endopod (Figures 1C, 6C) and two putative exopods (Figures 1C, 6C). Its length is circa two-thirds its width. The pleural regions of the shield's anterior-most segment are effaced but a transverse furrow is visible axially.

The tail fan (Figures 1A-C, 6A-C), attached to the posterior shield-like structure, is broad. It inserts at the end of the shield-like structure: one lateral terminus is visible ('tf' in Figure 6A-C). Its morphology, e.g., the posterior margin of the middle, cannot be described further because it is partly hidden underneath the matrix.

The frontal head limbs, with no clear terminus, reach a length of circa $16 \%$ of the total length of the body. They are upwardly curved and protrude from the ventral side of the head shield. The shaft is sub-rectangular, robust, and stout across its length. At least six podomeres, five of which bear a single endite per podomere with no auxiliary endites, taper distally. The length of each endite does not exceed the height of its podomere, which decrease in width distally. The frontal head limb, along which the endites alternate in length, is not 


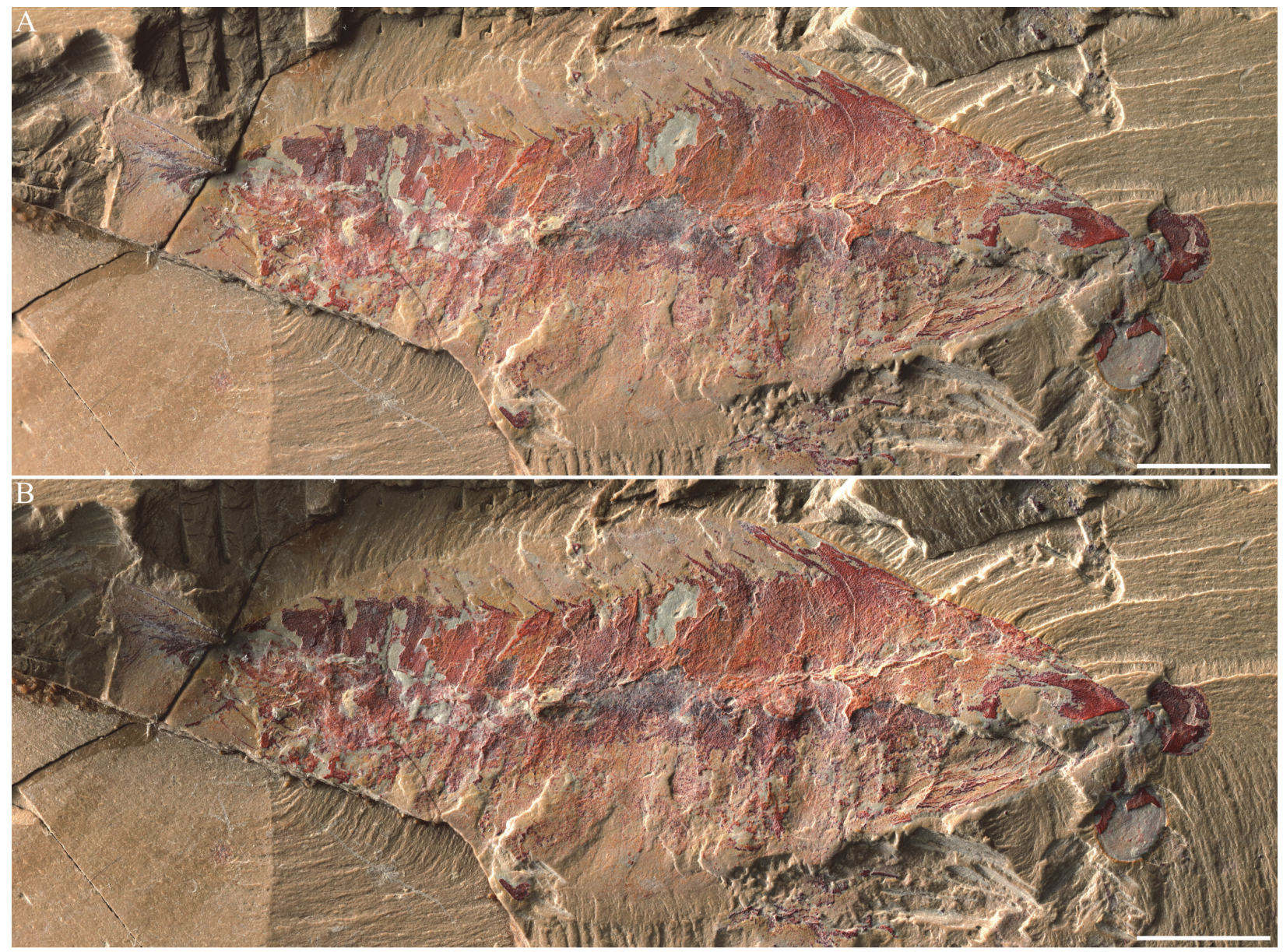

$\mathrm{C}$

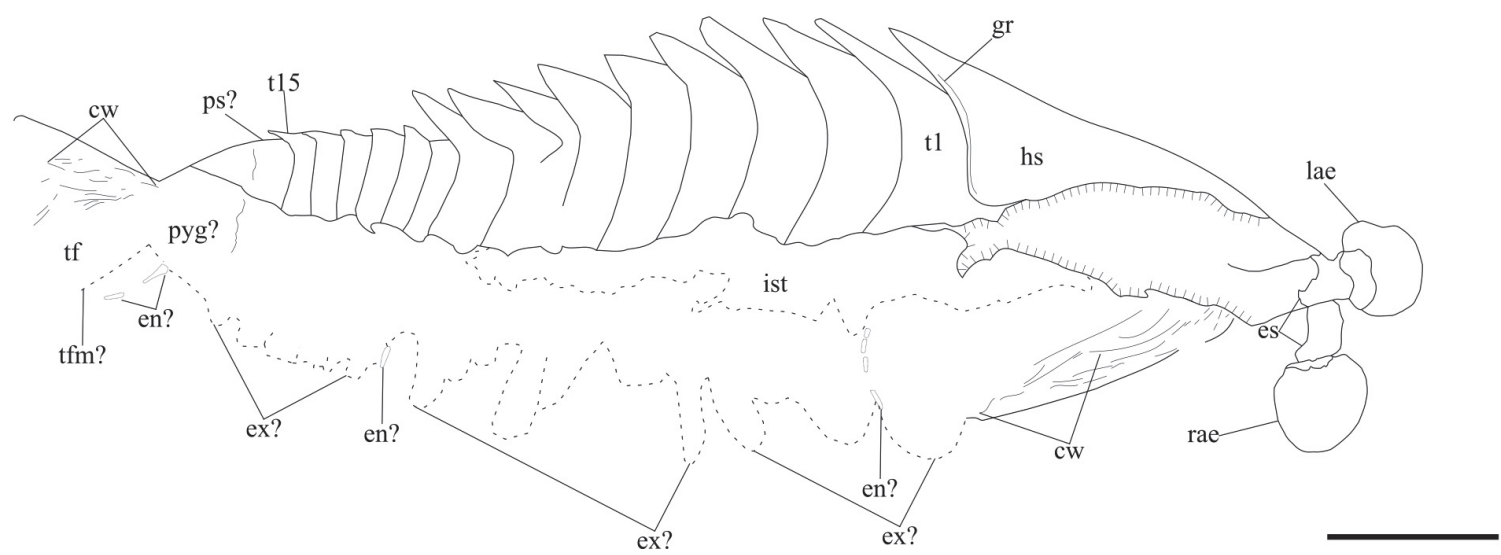

FIGURE 1. Fengzhengia mamingae gen. et sp. nov. (YKLP 11431a). A-B, lateral view (stereo pair) of the part (stereo images have a tilt of $20^{\circ}$ to emphasise topographic differences); C, composite line drawing of the same. All scale bars are $5 \mathrm{~mm}$. Abbreviations: ist, indeterminate soft tissue; $\mathrm{cW}$, compression wrinkle(s); en?, putative endopod podomere(s); es, eye stalk(s); ex?, putative exopod(s); gr, groove; hs, head shield; lae, left eye; ps?, putative pygidial segment; pyg?, putative pygidium; rae, right eye; tf, tail fan; tfm?, perceived margin of tail fan; $\mathrm{t} 1-15$, tergites 1 through 15. 

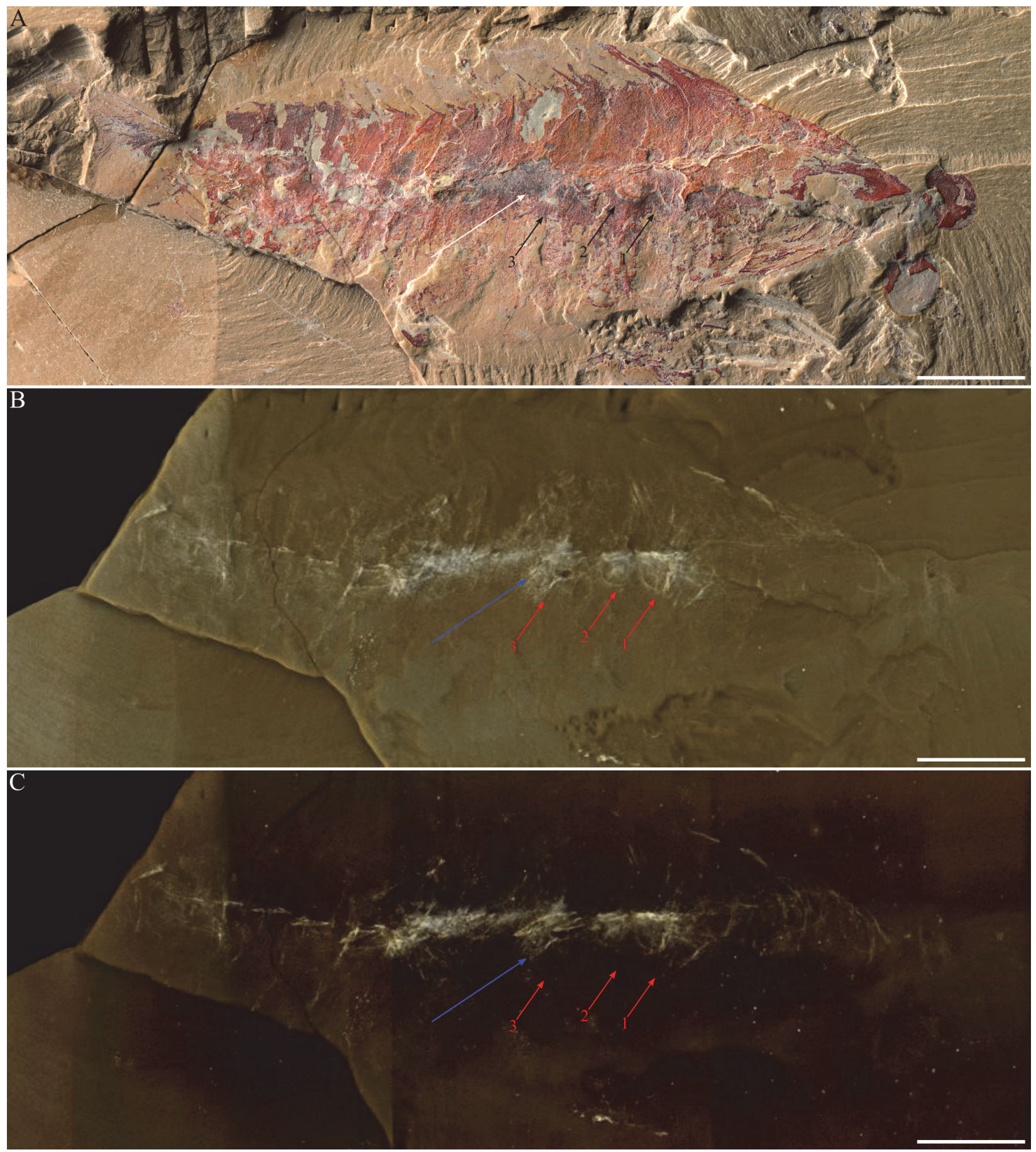

FIGURE 2. Fengzhengia mamingae gen. et sp. nov. (YKLP 11431a). A, lateral view of the part; B-C, tomographic models of the part - lateral view of the part with the matrix partially removed digitally and lateral view of the part with the matrix further removed digitally, respectively. All scale bars are $5 \mathrm{~mm}$. Blue and white arrowheads point to the tergopleurae of the third trunk segment and black and red arrowheads indicate the paddle shaped exopods of trunk limbs $1-3$. 

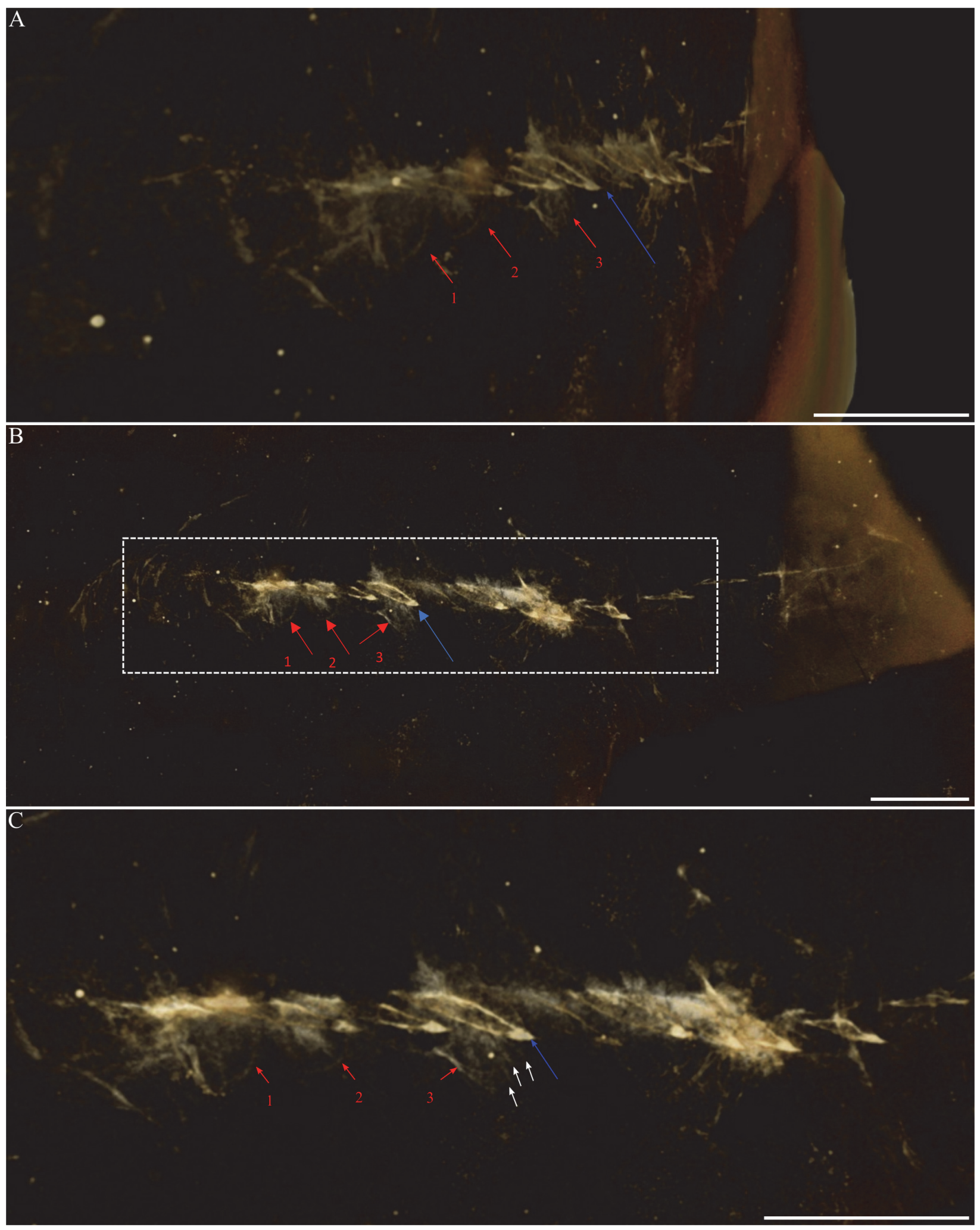

FIGURE 3. Fengzhengia mamingae gen. et sp. nov. (YKLP 11431a). A-C, tomographic models of the part. The specimen is orientated with the anterior facing left. All scale bars are $5 \mathrm{~mm}$. The blue arrowheads point to the tergopleural terminus of the third trunk segment and, the red arrowheads indicate the paddle-shaped exopods of trunk limbs 1-3 transverse sections through flattened lobate exopods that clearly extend beyond the tergopleural termini, and white arrowheads indicate exopod setae. Abbreviations: 1, trunk exopod 1; 2, trunk exopod 2; 3, trunk exopod 3. 


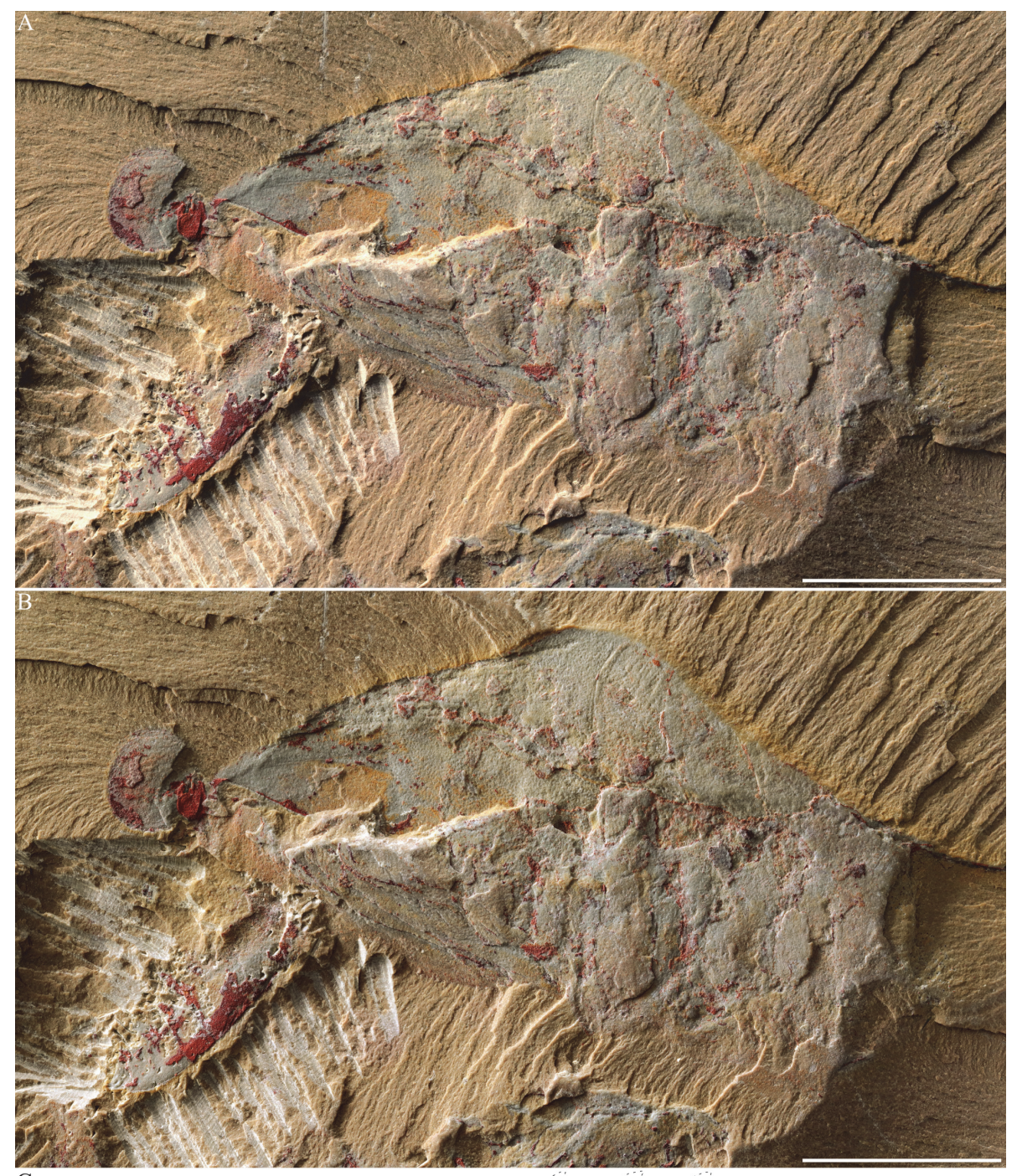

$\mathrm{C}$

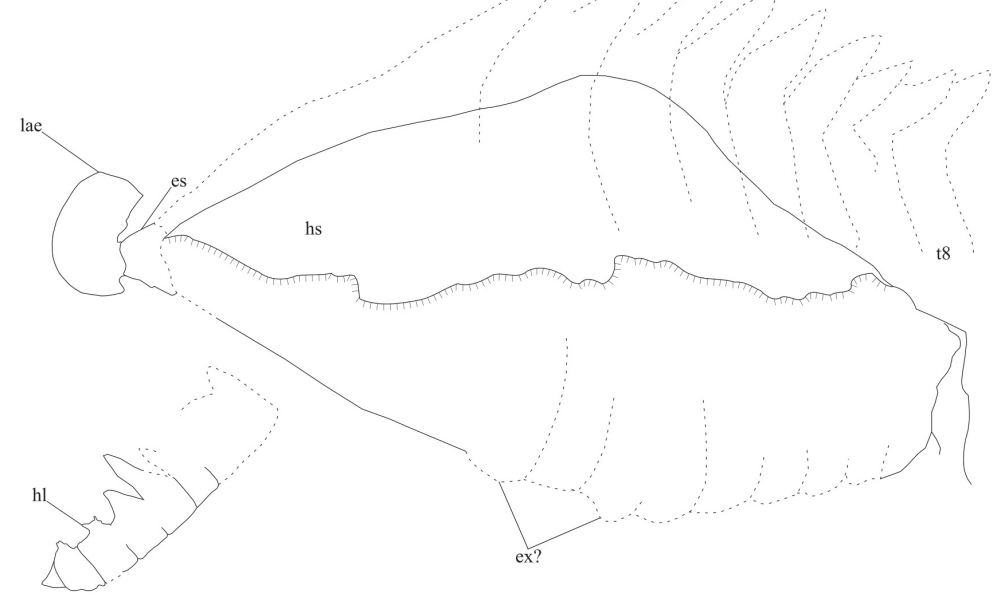

FIGURE 4. Fengzhengia mamingae gen. et sp. nov. (YKLP 11431b). A-B, lateral view (stereo pair) of the counterpart (stereo images have a tilt of $20^{\circ}$ to emphasise topographic differences); $\mathbf{C}$, composite line drawing of the same. All scale bars are $5 \mathrm{~mm}$. Abbreviations: es, eye stalk(s); ex?, putative exopod(s); hl, frontal head limb; hs, head shield; lae, left eye; t8, tergite 8 . 

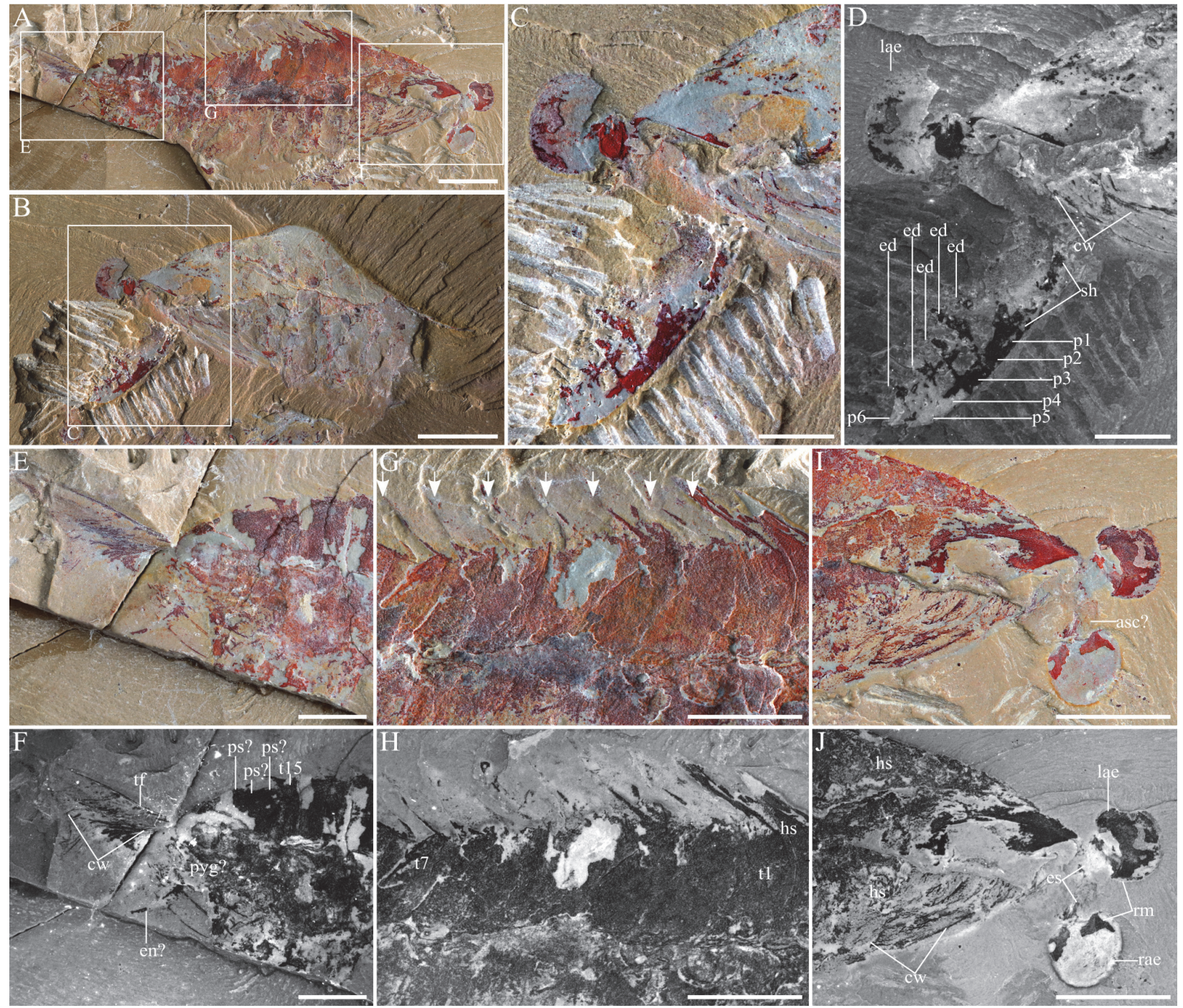

FIGURE 5. Fengzhengia mamingae gen. et sp. nov. (YKLP 11431). A, part (boxed regions are shown in E-J); B, counterpart (boxed regions are shown in $\mathrm{C}-\mathrm{D}$ ); $\mathbf{C}$, tungsten photography lighting of head region in $\mathrm{B}$; $\mathbf{E}$, posterior body region from $A ; \mathbf{G}$, trunk tergites from $A$; I, head region from $A ; \mathbf{D}, \mathbf{F}, \mathbf{H}, \mathbf{J}$, fluorescent photography lighting of the same. Arrowheads indicate medial axial spines. Scale bars are $5 \mathrm{~mm}(\mathrm{~A}-\mathrm{B}, \mathrm{I}-\mathrm{J}) ; 2 \mathrm{~mm}(\mathrm{C}-\mathrm{H})$. Abbreviations: asc?, putative anterior sclerite; cw, compression wrinkle(s); ed, endite(s); en?, putative endopod; es, eye stalk(s); hs, head shield; lae, left eye; p1-p6, podomeres 1 through 6; ps?, putative pygidial segment(s); pyg?, putative pygidium; rae, right eye; rm, rim of eye; sh, shaft of frontal head limb; tf, tail fan; t1, tergite 1; t7, tergite 7; t15, tergite 15.

situated close to the eyes but inserts circa onethird of the length of the head shield behind it.

Three trunk limbs, immediately posterior to the head shield, are concealed within the slab (Figure $2 \mathrm{~A}-\mathrm{C}$ ) and revealed by micro-CT (Figure $3 \mathrm{~A}$ C). Three paddle-shaped exopods that extend beyond the tergopleural termini (Figure $3 \mathrm{~A}-\mathrm{C}$ ), one per tergite, one putative endopod with four putative podomeres, and two putative podomeres in isolation (Figures 1C, 6C), are figured.

Indeterminate soft tissue (Figure $1 \mathrm{~A}-\mathrm{C}$ ): an indeterminate structure (Figures 1A-C, 5G-H), which runs through the central portion of the body, might be a trace of the gut. Its maximum diameter is about $2.2 \mathrm{~mm}$.

Remarks. Morphological features of Fengzhengia mamingae include body arthrodisation, limb biramy, and stalked compound eyes. The first and second are synapomorphies associated with Deuteropoda (Ortega-Hernández, 2016, table 4).

Fengzhengia mamingae exhibits a stout, anteroventral grasping appendage that is superficially like the frontal appendage of radiodonts, megacheirans, isoxyids, and certain other euar- 

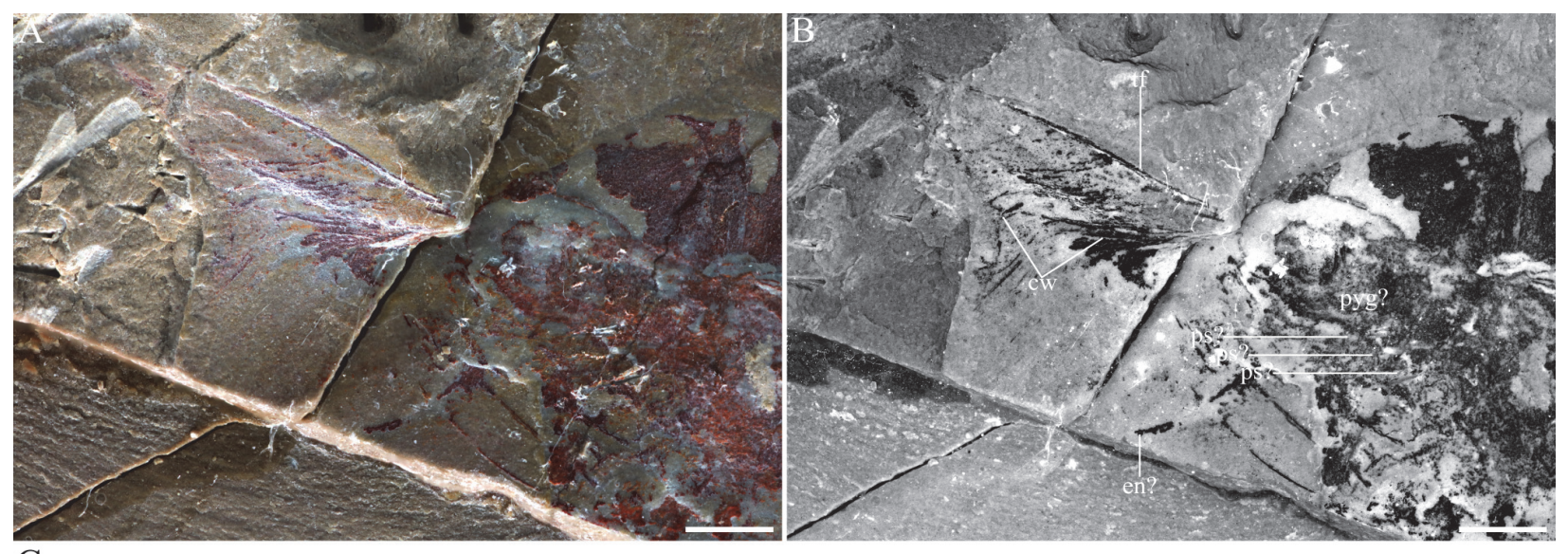

C

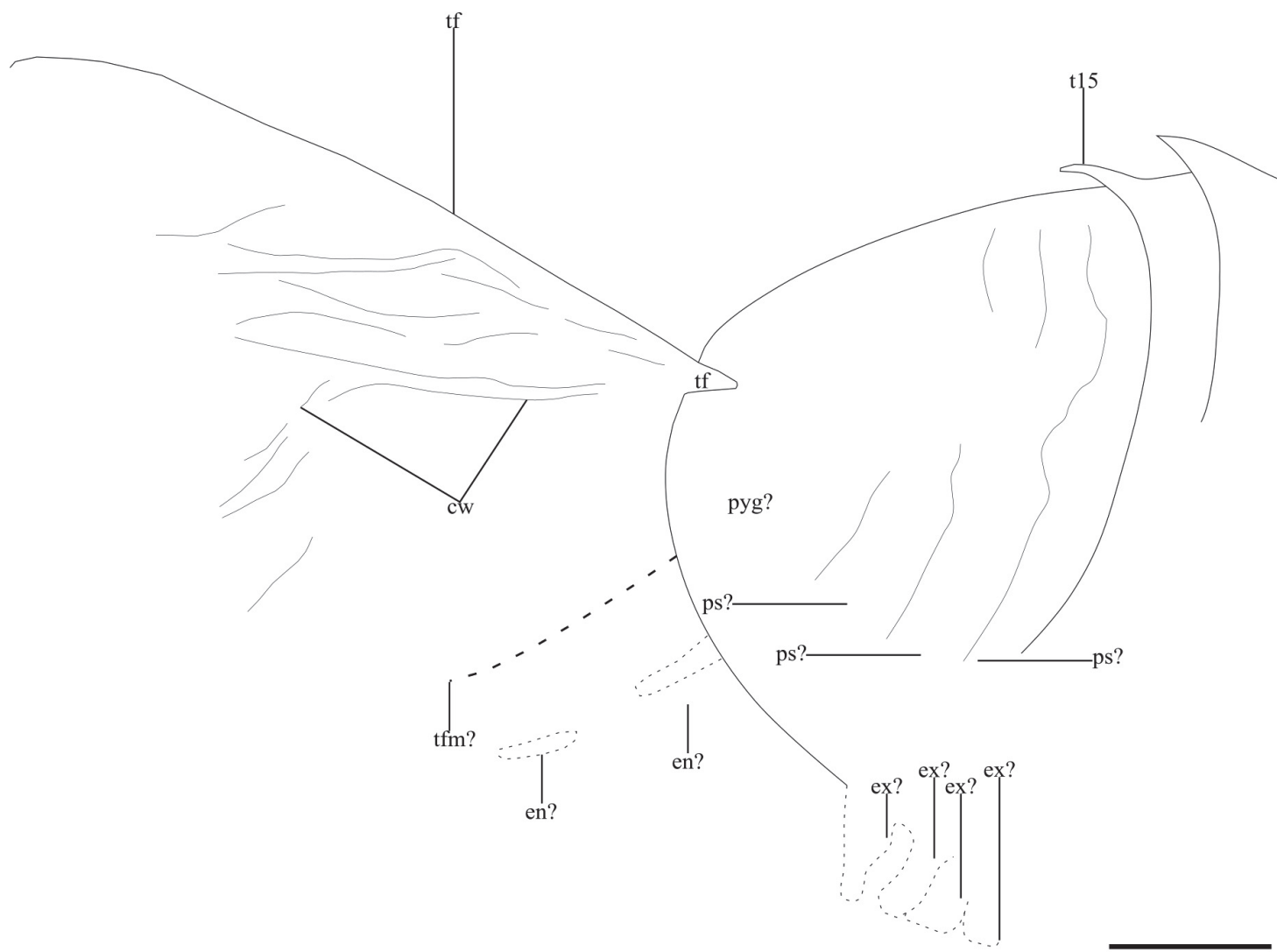

FIGURE 6. Fengzhengia mamingae gen. et sp. nov. (YKLP 11431). A-B, tungsten photography and fluorescent photography lighting of putative pygidium and tail fan, respectively; $\mathbf{C}$, interpretive line drawing of the same. All scale bars are $1 \mathrm{~mm}$. Abbreviations: cw, compression wrinkles; en?, putative endopod podomeres; ex?, putative exopod(s); ps?, putative pygidial segment(s); pyg?, putative pygidium; tf, tail fan; tfm?, perceived margin of tail fan; t15, tergite 15.

thropods, e.g., Bushizheia yangi and Kiisortoqia soperi. The upward orientation of the appendages in $F$. mamingae is shared with megacheirans and Kylinxia zhangi (reviewed in Zeng et al., 2020) and those isoxyids with raptorial rather than antenniform frontal appendages, e.g., Isoxys (Walcott, 1890) (see García-Bellido et al., 2009; Edgecombe, 2020). In contrast, the frontal appendages of radiodonts typically face downward, and typically bear a pivot joint (Wu et al., 2021), dorsal spines (Pates et al., 2021), and auxiliary enditic spines (Zeng et al., 2020), none of which are evident in $F$. mamingae. The lack of dorsal spines on the frontal appendage also distinguishes F. mamingae from Bushizheia yangi (cf. O'Flynn et al., 2020, figure 2A-B). 
TABLE 1. Length and width measurements (in $\mathrm{mm}$ ) of anatomical structures of Fengzhengia mamingae gen. et sp. nov. Note that tergite widths cannot be identified hence absent quantitative data, and the dimensions of podomere 6 , although given, are of an incompletely preserved podomere. Endites of podomeres 4 and 5 are also incompletely preserved.

\begin{tabular}{lcc}
\hline \multicolumn{1}{c}{ Morphological terms } & Length & Width \\
\hline General habitus & 38 & 13 \\
Head shield & 11 & 11 \\
Tergites 1-9 & $\leq 2$ & \\
Tergites 10-15 & $\leq 0.9$ & \\
Posterior shield-like structure & 4 & 5 \\
Tail fan & 4 & 5 \\
Frontal head limbs & 6 & 1.8 \\
Shaft & 1.9 & 1.8 \\
Podomere 1 (+ endite) & 0.7 & $0.9(1.7)$ \\
Podomere 2 (+ endite) & 0.8 & $0.89(2.2)$ \\
Podomere 3 (+ endite) & 0.8 & $0.88(1.6)$ \\
Podomere 4 (+ endite) & 0.8 & $0.87(1.4)$ \\
Podomere 5 (+ endite) & 0.7 & $0.86(1.2)$ \\
Podomere 6 & 0.4 & 0.6 \\
\hline
\end{tabular}

The frontal appendage in Fengzhengia mamingae is constructed from at least six podomeres, whereas those of megacheirans typically consist of five podomeres, therefore $F$. mamingae is not a megacheiran sensu Aria et al. (2020). F. mamingae also lacks evidence for the characteristic elbow joint and chelate tip of megacheiran 'great appendages' (cf. Edgecombe and Legg, 2014). In contrast to Kylinxia zhangi, a recently described deuteropod with similarities to both radiodonts and megacheirans (Zeng et al., 2020), the frontal appendage in $F$. mamingae exhibits a single rather than a double row of elongate triangular endites on the shaft and lacks auxiliary spines.

The head of Fengzhengia mamingae bears what appears to be a protuberance (Figure 5I), which could represent the anterior sclerite from which large, stalked, sub-circular (far more circular than elliptical) eyes protrude anterolaterally, as observed in, e.g., Odaraia alata Walcott, 1911 (e.g., Briggs, 1981; Ortega-Hernández, 2015); the peduncles' length (such as are visible laterally) is about equal to the eyes' diameter. The eyes bear marginal rims that may represent a flattened lens or corneal layers (Figures 1A-C, 5J).

The division of the trunk into an anterior series of nine broad tergites with medial axial spines, followed by a series of six comparatively narrow tergites that lack spines, resembles the thoracic- abdominal subdivision of fuxianhuiids. Despite these apparent similarities, neither part nor counterpart exhibits a pair of antennae or a pair of specialised post-antennal appendages (Chen et al., 2020); therefore, it is not a fuxianhuiid sensu Chen et al. (2020).

We interpret the posterior shield-like structure, based on the conjoined segments posterior to the last trunk articulation (Hughes et al., 2006) in Fengzhengia mamingae as a pygidium sensu Cotton and Braddy (2004), i.e., a posterior tagma consisting of several fused segments under a single tergite, which may or may not incorporate the postsegmental telson. Fengzhengia mamingae also shows a putative endopod attached to its posterior shield-like structure (Figure 6A-C). A pygidium similar to the posterior shield-like structure in F. mamingae is also present in Bushizheia yangi (O'Flynn et al., 2020), and the recently described stem mandibulate bivalved arthropod, Pakucaris apatis Izquierdo-López and Caron, 2021. If the posterior shield of $F$. mamingae is a pygidium, it adds to a growing number of pygidium-bearing arthropods and supports a phylogenetic scenario in which a pygidium is not synapomorphic for a clade composed of xandarellids, naraoiids, helmetiids, tegopeltids, and trilobites, but rather is plesiomorphic, with the structure being retained in certain groups (e.g., $B$. yangi, F. mamingae, and Artiopoda; discussed in O'Flynn et al., 2020; Izquierdo-López and Caron, 2021).

Fengzhengia mamingae resembles Kylinxia zhangi (Zeng et al., 2020) in having a subtriangular head shield with rounded genal angles; large, stalked compound eyes extending from under the head shield, which bear marginal rims; possibly also a pygidium merged from $\geq$ three somites articulated with a tail fan. However, there are further, significant morphological differences: (1) F. mamingae has 15 trunk tergites, of which the first nine are broad with medial spines, and the remaining six are narrow without spines, whereas $K$. zhangi has as many as 25 trunk tergites, which do not contrast in size; (2) the trilobation of tergites is effaced in $F$. mamingae, but prominent in K. zhangi; and (3) F. mamingae has no posterior stalked compound eyes on the head, whereas $K$. zhangi has two anterior and three posterior stalked compound eyes on the head (Zeng et al., 2020, figure 3).

In terms of preservation, Fengzhengia mamingae is laterally compressed, lies parallel to lamination, and is well-articulated, i.e., its tergites are preserved attached and its eyes are preserved in situ. This state of preservation suggests limited 


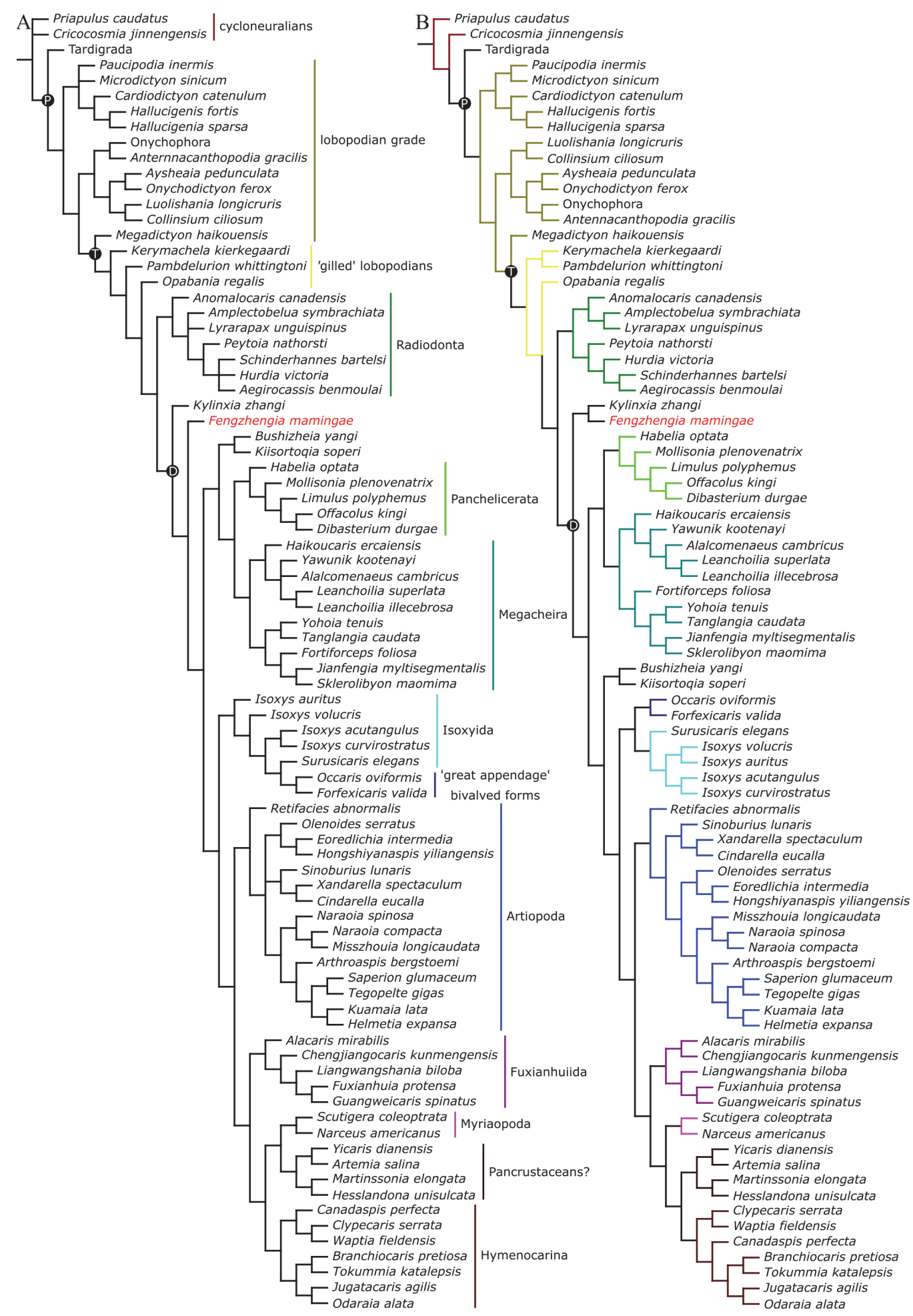

FIGURE 7. Consensus trees from Bayesian (left) and parsimony (right) analyses of panarthropod relationships based on a matrix of 283 characters and 84 taxa with deutocerebral frontal-most appendages inferred. A, 50\% majority-rule consensus tree from a Bayesian analysis; B, strict consensus of a single most parsimonious tree of 54.38597 steps (consistency index $=0.48$; retention index $=0.86$ ) from a parsimony analysis using implied character weighting (concavity constant $\mathrm{k}=3$ ). In the parsimony analysis Fengzhengia mamingae gen. et $\mathrm{sp}$. nov. is retrieved as the sister taxon to the early branching deuteropod Kylinxia zhangi Zeng, Zhao, and Huang in Zeng et al., 2020. In the Bayesian analysis F. mamingae is resolved as a deuteropod that bridges between $K$. zhangi and all other deuteropods. Abbreviations: D, Deuteropoda; P, Panarthropoda; T, total-group Euarthropoda. 
post-mortem transportation (e.g., Shu et al., 1999). Compression wrinkles in the head shield and tail fan suggest localised, weak sclerotisation.

\section{RESULTS}

In the first phylogenetic analysis (Appendix 1, Figure 7A-B) we coded the position of the frontal appendages as deutocerebral. The parsimony analysis yielded a single most parsimonious tree under implied character weighting (concavity constant $k=3$ ) (Legg et al., 2013). This single most parsimonious tree has a length of circa 54 , a tree length of 713 steps, a consistency index of 0.48 , and a retention index of 0.86 . Fengzhengia mamingae is retrieved as the sister taxon to the early branching deuteropod Kylinxia zhangi. In the Bayesian analysis, by contrast, F. mamingae is resolved as a deuteropod that bridges between $K$. zhangi and all other deuteropods.

The phylogenetic placement of Fengzhengia mamingae in the parsimony analysis is supported by the absence of circumoral structures in a radial arrangement, the presence of post-ocular tergal sclerotisation in the head, the absence of posteriormost lateral processes with lanceolate tips, the presence of arthropodised trunk appendages, and the presence of jointed legs or endopodites-characters 37,75 , and 146,167 , and 249 , respectively (Zeng et al., 2020). The Bayesian analysis, which reconstructs $F$. mamingae in an intermediate position between the earliest branching deuteropod, $K$. zhangi, and all other deuteropods, is supported by the absence of frontal-most appendages with endites bearing well-developed auxiliary spinescharacter 198 (Zeng et al., 2020), which are present in radiodonts, $K$. zhangi, and megacheirans, but absent in isoxyids (e.g., Fu et al., 2011a; Legg and Vannier, 2013) and other Cambrian euarthropods (Hou et al., 2017).

In the second phylogenetic analysis (Appendix 2) we coded the position of the frontal appendages as unknown (Appendix 2), which resulted in no change to the position of Fengzhengia mamingae in either parsimony or Bayesian analyses. A third analysis (Appendix 3 ), however, which featured the frontal appendage coded as protocerebral, shifted the position of $F$. mamingae in parsimony analysis; F. mamingae occupies a lower branch to Kylinxia zhangi and all other deuteropods.

Considering the uncertain identity of the subtriangular posterior shield-like structure, a pygidium was coded as present in the first three analyses but absent in a fourth (Appendix 4); this involved recoding character 151 (multiple posterior segments fused) and associated characters 152-155 (Zeng et al., 2020). This analysis assumed a deutocerebral identity for the frontal appendage, as in analysis 1 . The effect of coding a pygidium as absent did not change the position of Fengzhengia mamingae with respect to analysis 1 : i.e., it is an early branch of Deuteropoda.

\section{DISCUSSION}

The combination of characters in Fengzhengia mamingae suggests that it represents an early branch of Deuteropoda. Recent discoveries have posed challenges to established hypotheses of character evolution in this part of the tree, notably that of Kylinxia zhangi (Zeng et al., 2020), which apparently shares features typically associated with radiodonts, opabiniids, megacheirans, and artiopodans. Another Chengjiang arthropod, Bushizheia yangi, exhibits 'great appendage'-like frontal head limbs with a more typically artiopodan body form (O'Flynn et al., 2020; see also Jiao et al., 2021). At the same time, competing hypotheses of head limb homology continue to find support, resulting in uncertainty over the deep structure of the euarthropod tree (reviewed in Budd, 2021; see also Aria et al., 2020). In particular, a hypothesis of differing frontal appendage identity in radiodonts (protocerebral) compared to deuteropods (deutocerebral) can be challenged by contrasting interpretations of fossil structures and, in turn, the implied pattern of head reorganisation that must have occurred in this part of the tree (reviewed in Budd, 2021).

Fengzhengia mamingae cannot resolve between competing hypotheses of frontal appendage identity, which would require preservation of the nervous system (to establish the pattern of innervation of frontal appendages) and threedimensional reconstruction of the ventral part of the head (to test for the presence and position of a differentiated labrum). However, given that it is interpreted as an early branching deuteropod, it contributes to a growing number of euarthropods with character combinations that can potentially resolve the polarity of character transformations in this region of the tree. In particular, the documentation of an upwards-oriented frontal appendage with more than five podomeres of comparatively simple ornamentation adds to the known range of frontal appendage architectures. The combination of a frontal appendage with a tail fan, which possibly articulates with a pygidium-type structure, is remi- 


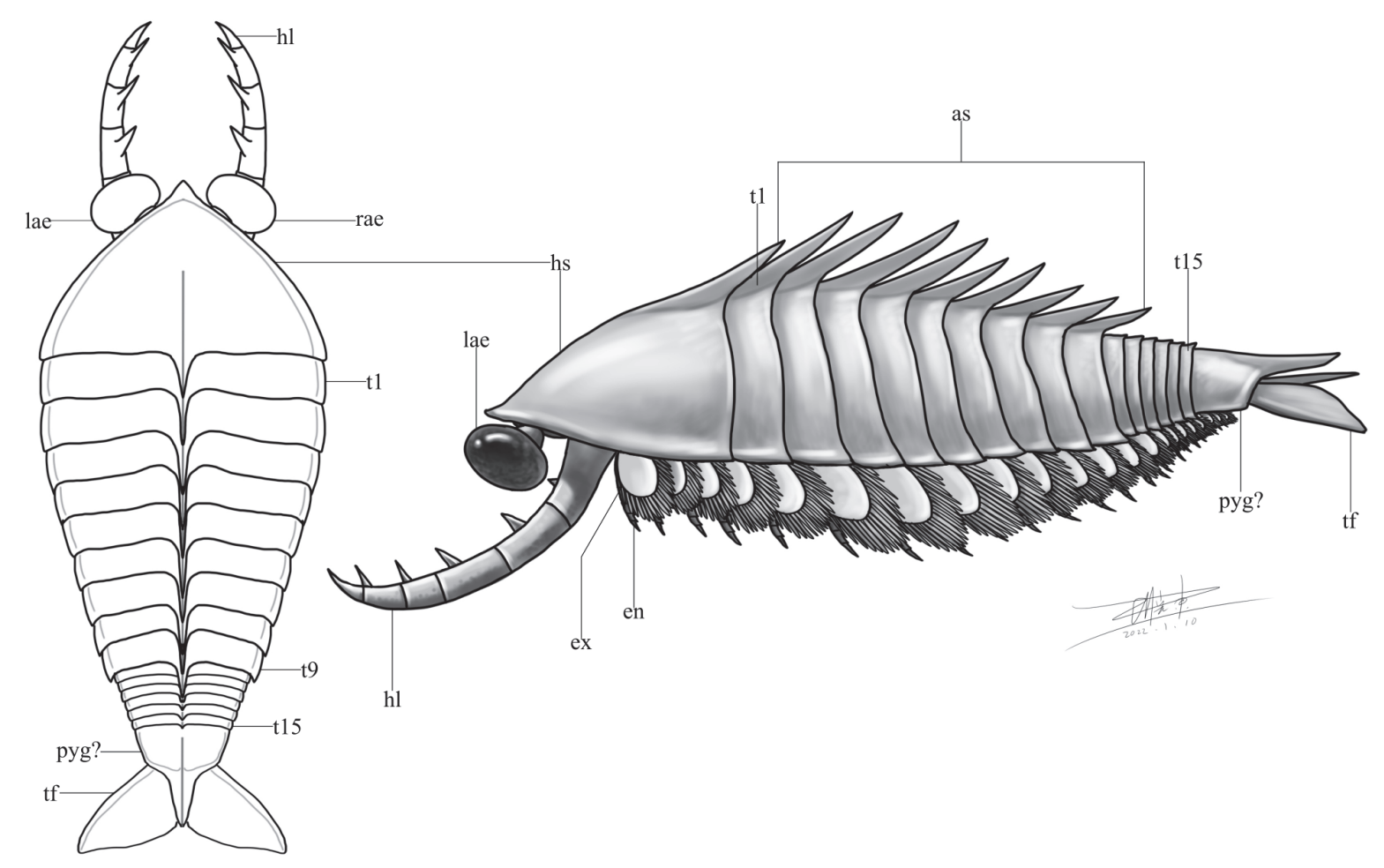

FIGURE 8. Diagrammatic reconstructions of Fengzhengia mamingae gen. et sp. nov. A, dorsal view; B, lateral view. The scale bar is $5 \mathrm{~mm}$. Abbreviations: as, medial axial spines; en, endopod; ex, exopod; hl, frontal head limb; hs, head shield; lae, left eye; pyg?, putative pygidium; rae, right eye; tf, tail fan; $\mathrm{t} 1$, tergite 1; t9, tergite 9; t15, tergite 15. Morphological details of the tail fan were partially inferred from Kylinxia zhangi Zeng, Zhao, and Huang in Zeng et al., 2020.

niscent of the condition in Kylinxia zhangi, and clearly this influences the outcome of our phylogenetic analyses, despite the many distinctions between these taxa. Overall, we consider any placement of $F$. mamingae in the tree to be tentative, pending the discovery of more material of this exceptionally rare Chengjiang arthropod. Nevertheless, the likely recognition of $F$. mamingae as an early branch of Deuteropoda with a novel character combination adds to the representation of taxa from this pivotal region of the euarthropod tree, and suggests that with further sampling of Cambrian Lagerstätten, we can come closer to understanding the profound transition in euarthropod evolution which led to the origins of modern arthropod lineages.

\section{PALAEOECOLOGY}

In the absence of direct evidence, the interpretation of the possible life habits of Fengzhengia mamingae must rest on inferences from its morphology and from other taxa. The frontal limbs of $F$. mamingae (Figures 8-9) may have been predatory, possibly analogous in their function to the "great appendage' of certain radiodonts and megachierans. Their spines are as robust as those of radiodonts and similar in length to those of amplectobeluids and anomalocaridids, and due to there being no apparent pivot joint between each podomere, we infer flexure at the base of the frontal appendages, similarly exhibited by the hurdiid radiodont Cambroraster falcatus Moysiuk and Caron, 2019 (see also Whittington and Briggs, 1985). Pivot joints are also absent in Caryosyntrips Daley and Budd, 2010, a radiodont with which $F$. mamingae shares a more similar frontal appendage morphology, i.e., without the typical hurdiid set of five elongate pectinate endites (Moysiuk and Caron, 2019) and with a segmented appendage that is elongate with each podomere bearing one 


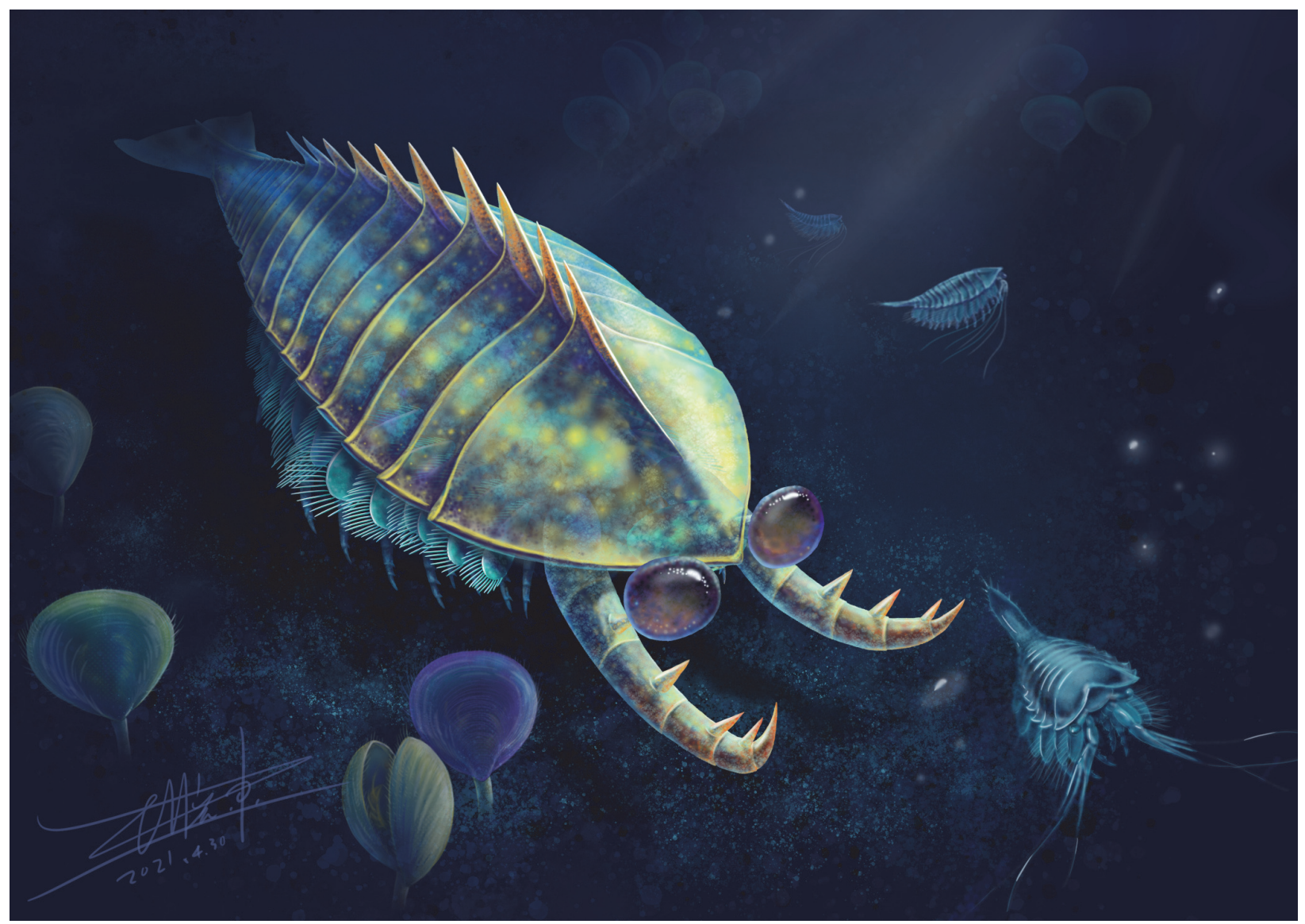

FIGURE 9. Artistic reconstruction of Fengzhengia mamingae gen. et sp. nov.

thick spine on its inner margin (cf. Daley and Budd, 2010). Since Caryosyntrips is thought to have moved its frontal appendages by pivoting at the basal attachment joint (Daley and Budd, 2010; Pates and Daley, 2017), perhaps the frontal appendages of $F$. maningae were also capable of a coordinated occlusive motion (cf. Pates et al., 2021). Zeng et al. (2020) suggests a similar function for the frontal appendages of Kylinxia zhangi, i.e., flexure is also exhibited by $K$. zhangi in the absence of a pivot joint (see their supplementary information, character 205).

The frontal appendages of Fengzhengia mamingae are typically larger and have more podomeres than those of antennate megacheirans such as Fortiforceps Hou and Bergström, 1997 (cf. Aria et al., 2020, figure 5A-B) and Jianfengia Hou, 1987 (cf. Aria et al., 2020, figure 5E), which have a two-part proximal peduncle connected by an elbow joint to a distal claw comprising four podomeres each with a long spine on the inner side (Hou et al., 2017). Fortiforceps foliosa Hou and Bergström, 1997 is thought to have used its elbow joint as a jack-knife: a mechanism also credited to Yohoia tenuis Walcott, 1912, another megacheiran (Haug et al., 2012).

In their evolutionary history, euarthropods have developed appendages specialised for swimming at several positions along the body (Perrier et al., 2015). The presence of a tail fan could be indicative of a nektobenthic habit (Figures 8-9). Alternatively, the tail fan of Fengzhengia mamingae could have enabled rapid changes in direction, as shown in an exploration of the swimming efficiency and manoeuvrability of Anomalocaris canadensis Whiteaves, 1892 deduced from direct hydrodynamic analysis (Sheppard et al., 2018).

In combination with its possible tail fan, Fengzhengia mamingae has a foreshortened body and extensive medial axial spines, which supply dorsal but not ventral cover. If it lived at or near the seabed, F. mamingae may have used its well-developed anteriorly positioned stalked eyes for searching out food, either to scavenge or to find prey (Hou et al., 2017), and its lamellar exopod setae for mechanical activity such as swimming or digging (Farley, 2010). The presence of large, stalked eyes and a pair of stout grasping append- 
ages have been interpreted as predatory in what are essentially nektonic animals (Fu et al., 2011b; Patterson et al., 2020).

Animals have evolved a range of adaptations for defence (Hou et al., 1995; Haug and Haug, 2014), and the idea of thwarting predatory tactics via dorsal axial spines draws a parallel between Fengzhengia mamingae and Guangweicaris spinatus Luo, Fu, and $\mathrm{Hu}$ in Luo et al., 2007, a fuxianhuiid from the lower Cambrian (Series 2, Stage 4), Guanshan biota (Wulongqing Member, Canglangpu Formation), of Yunnan Province (Chen et al., 2020). Dorsal axial spines that serve as antipredator defences (Knell and Fortey, 2005) are also found on trilobites (Fortey and Owens, 1999). In a quantitative study, Pates and Bicknell (2019) state that differences in repair frequencies of thoracic injuries are likely a result of predation intensity and not predator efficiency, and Nephrolenellus geniculatus Palmer, 1998, which has the longest spines in combination with the lowest repair frequency of the five species quantified in their study, deterred predators most successfully.

The lack of apparent flexure in the narrow posterior tergites of Fengzhengia mamingae does not suggest this region of the body was used to aid propulsion, contrary to the flexible abdominal region of the fuxianhuiid Guangweicaris spinatus (Chen et al., 2020). The tail fan of $F$. mamingae, however, may have aided in changing directions during natation and its flap-like exopods, albeit fairly small, may further suggest natation, as Zeng et al. (2020) suggest was the case with Kylinxia zhangi. Given that the exopods of $F$. mamingae are not as large as those of Haikoucaris (cf. Hou et al., 2017, figure 20.20) and more similar in size to those of $K$. zhangi (Zeng et al., 2020, figure 3B), we suggest that $F$. mamingae may have been a nektobenthic predator or scavenger and not necessarily an adept swimmer.

\section{CONCLUSION}

Fengzhengia mamingae possesses a fully arthrodised body and limbs and consequently rests comfortably within Euarthropoda (Aria, 2019). It has large frontal appendages which are otherwise typical of, e.g., radiodonts, megacheirans, and isoxyids, and biramous trunk appendages with short paddle-shaped exopods. It possesses a subtriangular head shield and a trunk bearing 15 tergites, the first nine with a medial spine not unlike those found on some trilobites (Fortey and Owens, 1999) and fuxianhuiids (Chen et al., 2020). Fengzhengia mamingae also has a possible pygidium articulated with a tail fan that resembles the posterior anatomy of Kylinxia zhangi. This structure in $F$. mamingae adds further evidence that pygidia were not uncommon in early branching euarthropods (see Izquierdo-López and Caron, 2021 who corroborate this).

Although the phylogenetic position of Fengzhengia mamingae is unstable with the available preserved morphology, our analysis suggests it is an early branch of the Deuteropoda, assuming a deutocerebral identity for the frontal appendage.

The results of phylogenetic analyses where the frontal appendage of Fengzhengia mamingae is coded as protocerebral, ipso facto placing it outside Deuteropoda, provides two scenarios: in parsimony analysis F. mamingae occupies a lower branch relative to Kylinxia zhangi and all other deuteropods, as would be expected. However, in Bayesian analysis is it resolved as a later branch to $K$. zhangi within Deuteropoda. It is beyond the scope of this article to attempt to solve the discrepancies stemming from different analytic tools, but the difficulties here stem from how ancestral state reconstructions vary. New datasets in combination with better material will form key tools in helping us to further understand the phylogenetic relationships within the euarthropod stem.

The dorsoventrally flattened exoskeleton, tail fan, and paddle-shaped exopods may be indicative of a nektobenthic mode of life for Fengzhengia mamingae. It likely used its stalked eyes and frontal appendages, by analogy with other Cambrian euarthropods, either to scavenge or find prey, and its spines may have performed a defensive role.

\section{ACKNOWLEDGEMENTS}

We thank Z. Yang for discovering, preparing, and donating the specimen to the Yunnan Key Laboratory for Palaeobiology, H. Mai (Yunnan Key Laboratory for Palaeobiology) for performing computed tomography scans, and X. Wang for artistic reconstructions. We also thank D. Audo (UMR 7207 CR2P, MNHN - Sorbonne Université CNRS, Paris) for preliminary discussions. We are indebted to the executive and handling editors and two anonymous reviewers for their helpful comments. This study is supported by the NSFC grant (41861134032) and Natural Science Foundation of Yunnan Province grants 2015HA021 and 2019DG050. This publication is undertaken under the auspices of the MEC International Joint Laboratory for Palaeobiology and Palaeoenvironment, Yunnan University, China. 


\section{AUTHOR CONTRIBUTIONS}

Y.L. secured the funding. R.J.O. and Y.L. devised the study. M.-X.Y. conducted the photography. All authors participated in the interpretation of the material. R.J.O. prepared the figures and table, conducted the phylogenetic analyses, and wrote the draft of the text with input from M.W., T.H.P.H., and Y.L.

\section{REFERENCES}

Aria, C. 2019. Reviewing the bases for a nomenclatural uniformization of the highest taxonomic levels in arthropods. Geological Magazine, 156:1463-1468. https://doi.org/10.1017/S0016756819000475

Aria, C., Zhao, F.-C., Zeng, H., Guo, J., and Zhu, M. 2020. Fossils from South China redefine the ancestral euarthropod body plan. BMC Evolutionary Biology, 20:4. https://doi.org/10.1186/s12862-019-1560-7

Bengtson, S. 2000. Teasing fossils out of shales with cameras and computers. Palaeontologia Electronica, 3.1.4A:1-14. https://palaeo-electronica.org/2000_1/fossils/issue1_00.htm

Bousfield, E.L. 1995. A contribution to the natural classification or Lower and Middle Cambrian arthropods: food-gathering and feeding mechanisms. Amphipacifica, 2:3-33.

Briggs, D.E.G. 1981. The arthropod Odaraia alata Walcott, Middle Cambrian, Burgess Shale, British Columbia. Philosophical Transactions of the Royal Society B, 291:1056. https://doi.org/10.1098/rstb.1981.0007

Budd, G.E. 1996. The morphology of Opabinia regalis and the reconstruction of the arthropod stem-group. Lethaia, 29:1-14. https://doi.org/10.1111/j.1502-3931.1996.tb01831.x

Budd, G.E. 2021. The origin and evolution of the euarthropod labrum. Arthropod Structure and Development, 62:101048. https://doi.org/10.1016/j.asd.2021.101048

Chen, H., Legg, D.A., Zhai, D.-Y., Liu, Y., and Hou, X.-G. 2020. New data on the anatomy of fuxianhuiid arthropod Guangweicaris spinatus from the lower Cambrian Guanshan Biota, Yunnan, China. Acta Palaeontologica Polonica, 65:139-148. https://doi.org/10.4202/app.00508.2018

Cong, P.-Y., Ma, X.-Y., Hou, X.-G., Edgecombe, G.D., and Strausfeld, N.J. 2014. Brain structure resolves the segmental affinity of anomalocaridid appendages. Nature, 513:538-542. https://doi.org/10.1038/nature13486

Collins, D. 1996. The "evolution" of Anomalocaris and its classification in the arthropod class Dinocarida (nov.) and order Radiodonta (nov.). Journal of Paleontology, 70:280-293. https://doi.org/10.1017/s0022336000023362

Cotton, T.J. and Braddy, S.J. 2004. The phylogeny of arachnomorph arthropods and the origin of the Chelicerata. Earth and Environmental Science Transactions of the Royal Society of Edinburgh, 94:169-193. https://doi.org/10.1017/S0263593300000596

Daley, A.C., Budd, G.E., Caron, J.B., Edgecombe, G.D., and Collins, D. 2009. The Burgess Shale anomalocaridid Hurdia and its significance for early euarthropod evolution. Science, 323:1597-1600. https://doi.org/10.1126/science.1169514

Daley, A.C. and Budd, G.E. 2010. New anomalocaridid appendages from the Burgess Shale, Canada. Palaeontology, 53:721-738. https://doi.org/10.1111/j.1475-4983.2010.00955.x

Daley, A.C., Antcliffe, J.B., Drage, H.B., and Pates, S. 2018. Early fossil record of Euarthropoda and the Cambrian Explosion. Proceedings of the National Academy of Sciences of the United States of America, 115:5323-5331. https://doi.org/10.1073/pnas.1719962115

Du, K.-S., Ortega-Hernández, J., Yang, J., and Zhang, X.-G. 2018. A soft-bodied euarthropod from the early Cambrian Xiaoshiba Lagerstätte of China supports a new clade of basal artiopodans with dorsal ecdysial sutures. Cladistics, 35:269-281. https://doi.org/10.1111/cla.12344

Edgecombe, G.D. 2020. Arthropod origins: integrating palaeontological and molecular evidence. Annual Review of Ecology, Evolution, and Systematics, 51:1-25. https://doi.org/10.1146/ annurev-ecolsys-011720-124437

Edgecombe, G.D. and Legg, D.A. 2014. Origins and early evolution of arthropods. Palaeontology, 57:457-468. https://doi.org/10.1111/pala.12105 
Farley, R.D. 2010. Book gill development in embryos and first and second instars of the horseshoe crab Limulus polyphemus L. (Chelicerata, Xiphosura). Arthropod Structure \& Development, 39: 369-381. https://doi.org/10.1016/j.asd.2010.04.001

Fortey, R.A. and Owens, R.M. 1999. The Trilobite exoskeleton, p. 537-562. In Savazzi, E. (ed.), Functional Morphology of the Invertebrate Exoskeleton. Wiley, New York.

Fu, D.-J., Zhang, X.-L., and Shu D.-G. 2011a. Soft anatomy of the Early Cambrian arthropod Isoxys curvirostratus from the Chengjiang biota of South China with a discussion on the origination of great appendages. Acta Paleontologica Polonica, 56:843-852. https://doi.org/10.4202/app.2010.0090

Fu, D.-J., Zhang, X.-L., and Shu, D.-G. 2011b. A venomous arthropod in the Early Cambrian Sea. Chinese Science Bulletin, 56:1532-1534. https://doi.org/10.1007/s11434-011-4371-6

García-Bellido, D.C., Vannier, J., and Collins, D. 2009. Soft-part preservation in two species of the arthropod Isoxys from the middle Cambrian Burgess Shale or British Columbia, Canada. Acta Palaeontologica Polonica, 54:699-712. https://doi.org/10.4202/app.2009.0024

Goloboff, P.A. and Catalano, S.A. 2016. TNT, version 1.5, with a full implementation of phylogenetic morphometrics. Cladistics, 32:221-238. https://doi.org/10.1111/cla.12160

Haug, C. and Haug, J.T. 2014. Defensive enrolment in mantis shrimp larvae (Malacostraca: Stomatopoda). Contributions to Zoology, 83:185-194. https://doi.org/10.1163/18759866-08303003

Haug, J.T., Haug, C., and Ehrlich, M. 2008. First fossil stomatopod larva (Arthropoda: Crustacea) and a new way of documenting Solnhofen fossils (Upper Jurassic, Southern Germany). Palaeodiversity, 1:103-109.

Haug, J.T., Haug, C., Kutschera, V., Mayer, G., Maas, A., Liebau, S., Castellani, C., Wolfram, U., Clarkson, E.N.K., and Waloszek, D. 2011. Autofluorescence imaging, an excellent tool for comparative morphology. Journal of Microscopy, 244:259-272. https://doi.org/10.1111/j.1365-2818.2011.03534.x

Haug, J.T., Waloszek, D., Maas, A., Liu Y., and Haug, C. 2012. Functional morphology, ontogeny and evolution of mantis shrimp?like predators in the Cambrian. Palaeontology, 55:369-399. https://doi.org/10.1111/j.1475-4983.2011.01124.x

Haug, J.T., Müller, C.H.G., and Sombke, A. 2013. A centipede nymph in Baltic amber and a new approach to document amber fossils. Organisms Diversity and Evolution, 13:425-432. https://doi.org/10.1007/s13127-013-0129-3

Haug, J.T., Müller, P., and Haug, C. 2018. The ride of the parasite: A 100-million-year-old mantis lacewing larva captured while mounting its spider host. Zoological Letters, 4:1-8. https://doi.org/10.1186/s40851-018-0116-9

Hou, X.-G. 1987. Two new arthropods from Lower Cambrian, Chengjiang, eastern Yunnan. Acta Palaeontologica Sinica, 26:236-256. (In Chinese with English summary)

Hou, X.-G., Bergström, J., and Ahlberg, P. 1995. Anomalocaris and other large animals in the Lower Cambrian Chengjiang fauna of southwest China. GFF, 117:163-183. https://doi.org/10.1080/11035899509546213

Hou, X.-G. and Bergström, J. 1997. Arthropods of the Lower Cambrian Chengjiang fauna, southwest China. Fossils and Strata, 45:1-116.

Hou, X.-G., Siveter, D.J., Siveter, D.J., Aldridge, R.J., Cong, P.-Y., Gabbott, S.E., Ma, X.-Y., Purnell, M.A., and Williams, M. 2017. The Cambrian Fossils of Chengjiang, China: The Flowering of Early Animal Life, Second Edition. Wiley-Blackwell, Chichester, UK.

Hughes, N.C., Minelli, A., and Fusco, G. 2006. The ontogeny of trilobite segmentation: a comparative approach. Palaeobiology, 32:602-627. https://doi.org/10.1666/06017.1

Izquierdo-López, A. and Caron, J.-B. 2021. A Burgess Shale mandibulate arthropod with a pygidium: a case of convergent evolution. Papers in Palaeontology, 7:1877-1894. https://doi.org/10.1002/spp2.1366

Jiao, D.-G., Pates, S., Lerosey-Aubril, R., Ortega-Hernández, J., Yang, J., Lan, T., and Zhang, X.-G. 2021. New multipodomerous appendages of stem-group euarthropods from the Cambrian (Stage 4) Guanshan Konservat-Lagerstätte. Royal Society Open Science, 8:211134. https://doi.org/10.1098/rsos.211134

Knell, R.J. and Fortey, R.A. 2005. Trilobite spines and beetle horns: sexual selection in the Palaeozoic? Biological Letters, 1:196-199. https://doi.org/10.1098/rsbl.2005.0304

Lankester, R.E. 1904. The structure and classification of the Arthropoda. Quarterly Journal of Microscopical Science, 47:523-582. https://doi.org/10.1242/jcs.s2-47.188.523 
Legg, D. and Vannier, J. 2013. The affinities of the cosmopolitan arthropod Isoxys and its implications for the origin of arthropods. Lethaia, 46:540-550.

https://doi.org/10.1111/let.12032

Legg, D., Sutton, M.D., and Edgecombe, G. 2013. Arthropod fossil data increase congruence of morphological and molecular phylogenies. Nature Communications, 4:2485. https://doi.org/10.1038/ncomms3485

Lewis, P.O. 2001. A likelihood approach to estimating phylogeny from discrete morphological character data. Systematic Biology, 50:913-925. https://doi.org/10.1080/106351501753462876

Liu, Y., Ortega-Hernández, J., Zhai, D.-Y., and Hou, X.-G. 2020. A reduced labrum in a Cambrian great-appendage euarthropod. Current Biology, 30:3057-3061. https://doi.org/10.1016/ j.cub.2020.05.085

Luo, H., Fu, X.-P., Hu, S.-X., Li, Y., Hou, S.-G., You, T., Pang, J.-Y., and Liu, Q. 2007. A new arthropod, Guangweicaris Luo, Fu et Hu gen. nov. from the Early Cambrian Guanshan Fauna, Kunming, China. Acta Geologica Sinica, 81:1-7.

Ma, X.-Y., Hou, X.-G., Edgecombe, G.D., and Strausfeld, N.J. 2012. Complex brain and optic lobes in an early Cambrian arthropod. Nature, 490:258-261. https://doi.org/10.1038/nature11495

Moysiuk, J. and Caron, J-B. 2019. A new hurdiid radiodont from the Burgess Shale evinces the exploitation of Cambrian infaunal food sources. Proceedings of the Royal Society B, 286:20191079. https://doi.org/10.1098/rspb.2019.1079

Nixon, K.C. 1999. The parsimony ratchet, a new method for rapid parsimony analysis. Cladistics, 15:407-414. https://doi.org/10.1111/j.1096-0031.1999.tb00277.x

O'Flynn, R.J., Audo, D., Williams, M., Zhai, D.-Y., Chen, H., and Liu, Y. 2020. A new euarthropod with 'great appendage'-like frontal head limbs from the Chengjiang Lagerstätte, Southwest China. Palaeontologia Electronica. 23(2):a36. https://doi.org/10.26879/1069

Ortega-Hernández, J. 2015. Homology of head sclerites in Burgess Shale euarthropods. Current Biology, 25:12. https://doi.org/10.1016/j.cub.2015.04.034

Ortega-Hernández, J. 2016. Making sense of 'lower' and 'upper' stem-group Euarthropoda, with comments on the strict use of the name Arthropoda von Siebold, 1848. Biological Reviews, 91:255-273. https://doi.org/10.1111/brv.12168

Ortega-Hernández, J., Janssen, R., and Budd, G.E. 2017. Origin and evolution of the panarthropod head - a palaeobiological and developmental perspective. Arthropod Structure \& Development, 46:354-379. https://doi.org/10.1016/j.asd.2016.10.011

Ortega-Hernández, J., Lerosey-Aubril, R., and Pates, S. 2019. Proclivity of nervous system preservation in Cambrian Burgess Shale-type deposits. Proceedings of the Royal Society B, 286:20191370. https://doi.org/10.1098/rspb.2019.2370

Palmer, A.R. 1998. Terminal Early Cambrian extinction of the Olenellina: documentation from the Pioche Formation, Nevada. Journal of Paleontology, 72:650-672. https://doi.org/10.1017/s0022336000040373

Pates, S. and Daley, A.C. 2017. Caryosyntrips: a radiodontan from the Cambrian of Spain, USA and Canada. Palaeontology, 3:461-470. https://doi.org/10.1002/spp2.1084

Pates, S. and Bicknell, R.D.C. 2019. Elongated thoracic spines as potential predatory deterrents in olenelline trilobites from the lower Cambrian of Nevada. Palaeogeography, Palaeoclimatology, Palaeoecology, 516:295-306. https://doi.org/10.1016/j.palaeo.2018.12.013

Pates, S., Lerosey-Aubril, R., Daley, A.C., Kier, C., Bonino, E., and Ortega-Hernández, J. 2021. The diverse radiodont fauna from the Marjum Formation of Utah, USA (Cambrian: Drumian). PeerJ, 9:e10509. https://doi.org/10.7717/peerj.10509

Patterson, J.R., Edgecombe, G.D., and García-Bellido, D.C. 2020. Disparate compound eyes of Cambrian radiodonts reveal their development growth mode and diverse visual ecology. Science Advances, 6:eabc6721. https://doi.org/10.1126/sciadv.abc6721

Perrier, V., Williams, M., and Siveter, D.J. 2015. The fossil record and palaeoenvironmental significance of marine arthropod zooplankton. Earth-Science Reviews, 146:146-162. https://doi.org/10.1016/j.earscirev.2015.02.003

Rambaut, A., Drummond, A.J., Xie, D., Baele, G., and Suchard, M.A. 2018. Posterior summarization in Bayesian phylogenetics using Tracer 1.7. Systematic Biology, 67:901-904. https://doi.org/10.1093/sysbio/syy032 
Ronquist, F., Teslenko, M., van der Mark, P., Ayres, D.L., Darling, A., Höhna, S., Larget, B., Liu, L., Suchard, M.A., and Huelsenbeck, J.P. 2012. MrBayes 3.2: efficient Bayesian phylogenetic inference and model choice across a large model space. Systematic Biology, 61:539-542. https://doi.org/10.1093/sysbio/sys029

Schneider, C.A., Rasband, W.S., and Eliceriri, K.W. 2012. NIH Image to ImageJ: 25 years of image analysis. Nature Methods, 9:671-675. https://doi.org/10.1038/nmeth.2089

Sheppard, K.A., Rival, D.E., and Caron, J.-B. 2018. On the hydrodynamics of Anomalocaris tail fins. Integrative and Comparative Biology, 58:703-711. https://doi.org/10.1093/icb/icy014

Shu, D.-G., Vannier, J., Luo, H.-L., Chen, L., Zhang, X.-L., and Hu, S.-X. 1999. Anatomy and lifestyle of Kunmingella (Arthropoda, Bradoriida) from the Chengjiang fossil Lagerstätte (lower Cambrian; Southwest China). Lethaia, 32:279-298. https://doi.org/10.1111/j.1502-3931.1999.tb00547.x

Smith, M.R. and Ortega-Hernández J. 2014. Hallucigenia's onychophoran-like claws and the case for Tactopoda. Nature, 514:363-366. https://doi.org/10.1038/nature13576

Stein, M. 2010. A new arthropod from the Early Cambrian of North Greenland, with a 'great appendage'-like antennula. Zoological Journal of the Linnean Society, 158:477-500. https://doi.org/10.1111/j.1096-3642.2009.00562.x

Strausfeld, N.J., Ma, X.-Y., Edgecombe, G.D., Fortey, R.A., Land, M.F., Liu, Y., Cong, P.-Y., and Hou, X.-G. 2016. Arthropod eyes: the early Cambrian fossil record and divergent evolution of visual systems. Arthropod Structure \& Development, 45:152-172. https://doi.org/10.1016/j.asd.2015.07.005

Tanaka, G., Hou, X.-G., Ma, X.-Y., Edgecombe, G.D., and Strausfeld. N.J. 2013. Chelicerate neural ground pattern in a Cambrian great appendage arthropod. Nature, 502:364-367. https://doi.org/10.1038/nature12520

Vannier, J., Liu, J., Lerosey-Aubril, R., Vinther, J. and Daley, A.C. 2014. Sophisticated digestive systems in early arthropods. Nature Communications, 5:1-9. https://doi.org/10.1038/ncomms4641

Walcott, C.D. 1890. The fauna of the Lower Cambrian or Olenellus Zone. Reports of the U.S. Geological Survey, 10:509-763.

Walcott, C.D. 1911. Middle Cambrian Holothurians and Medusae. Smithsonian Miscellaneous Collections, 57:41-68.

Walcott, C.D. 1912. Middle Cambrian Branchiopoda, Malacostraca, Trilobita and Merostomata. Smithsonian Miscellaneous Collections, 57:145-228.

Whiteaves, J.F. 1892. Description of a new genus and species of Phyllocarid Crustacea from the Middle Cambrian of Mount Stephen, B.C. Canadian Record of Science, 5:205-208.

Whittington, H.B. and Briggs, D.E.G. 1985. The largest Cambrian animal, Anomalocaris, Burgess Shale, British Columbia. Philosophical Transactions of the Royal Society of London. B, Biological Sciences, 309:569-609. https://doi.org/10.1098/rstb.1985.0096

Wu, Y., Ma, J.-X., Lin, W.-L., Sun, A., Zhang, X.-L., and Fu, D.-J. 2021. New anomalocaridids (Panarthropoda: Radiodonta) from the lower Cambrian Chengjiang Lagerstätte: Biostratigraphic and palaeobiogeographic implications. Palaeogeography, Palaeoclimatology, Palaeoecology, 569:110333. https://doi.org/10.1016/j.palaeo.2021.110333

Zeng, H., Zhao, F.-C., Niu, K.-C., Zhu, M.-Y., and Huang, D.-Y. 2020. An early Cambrian euarthropod with radiodont-like raptorial appendages. Nature, 588:101-105. https://doi.org/10.1038/s41586-020-2883-7

Zhu, M.-Y., Zhu, J.-M., and Li, J.-X. 2001. Sedimentary environments of the Early Cambrian Chengjiang biota: sedimentology of the Yu'anshan Formation in Chengjiang County, Eastern Yunnan. Acta Palaeontologica Sinica, 40:80-105. 


\section{APPENDICES}

\section{APPENDIX 1.}

Frontal head limbs of Fengzhengia mamingae gen. et sp. nov. coded as deutocerebral and pygidium present. (NEX files are downloadable in one zip file from https://palaeo-electronica.org/ content/2022/3551-a-new-chengjiang-euarthropod.)

\section{APPENDIX 2.}

Frontal head limbs of Fengzhengia mamingae gen. et sp. nov. coded as unknown and pygidium present. (NEX files are downloadable in one zip file from https://palaeo-electronica.org/content/ 2022/3551-a-new-chengjiang-euarthropod.)

\section{APPENDIX 3.}

Frontal head limbs of Fengzhengia mamingae gen. et sp. nov. coded as protocerebral and pygidium present. (NEX files are downloadable in one zip file from https://palaeo-electronica.org/content/2022/3551-a-new-chengjiang-euarthropod.)

\section{APPENDIX 4.}

Frontal head limbs of Fengzhengia mamingae gen. et sp. nov. coded as deutocerebral and pygidium absent. (NEX files are downloadable in one zip file from https://palaeo-electronica.org/ content/2022/3551-a-new-chengjiang-euarthropod.) 